\title{
Topical Application of St. John's Wort (Hypericum perforatum)
}

Authors

Affiliations
Ute Wölfle ${ }^{1}$, Günter Seelinger ${ }^{2}$, Christoph M. Schempp ${ }^{1}$

${ }^{1}$ Section skintegral, Department of Dermatology, University Medical Center Freiburg, Freiburg, Germany

${ }^{2}$ Medical Services Dr. Seelinger, Berlin, Germany
Key words

- St. John's wort

- Hypericum perforatum

- Hypericaceae

- topical application

- dermatology

\section{Abstract \\ $\nabla$}

St. John's wort (Hypericum perforatum) has been intensively investigated for its antidepressive activity, but dermatological applications also have a long tradition. Topical St. John's wort preparations such as oils or tinctures are used for the treatment of minor wounds and burns, sunburns, abrasions, bruises, contusions, ulcers, myalgia, and many others. Pharmacological research supports the use in these fields. Of the constituents, naphthodianthrones (e.g., hypericin) and phloroglucinols (e.g., hyperforin) have interesting pharmacological profiles, including antioxidant, antiinflammatory, anticancer, and antimicrobial activities. In addition, hyperforin stimulates growth

\section{Introduction}

$\nabla$

Hypericum perforatum L. (St. John's wort, SJW) (Hypericaceae) has made a career as one of the most prominent and best investigated medical plants during the last two decades, the focus of interest clearly being on its potential as an herbal antidepressant. Traditional use, however, was also characterized by external applications from the beginning, mainly in the form of oils and tinctures. One of the earliest known mentions of SJW as a medical plant is found in the Naturalis Historiae by Pliny the Elder (23-79 A.D.) [1] as a treatment for burns, but also internally as an astringent which arrests diarrhea, and as a diuretic. Many other external applications of SJW are listed in popular and in scientific literature: smaller wounds, sunburns, blunt traumata, ulcers, varicose, hemorrhoids, myalgia, sciatica, rheumatism, lumbago, cramps, decubitus, keloid scars, and tooth extraction, based on folk tradition, medical experience, or even on the doctrine of signatures, which suggested that a "wounded" (perforated) plant is intended by nature to cure wounds $[2,3]$. and differentiation of keratinocytes, and hypericin is a photosensitizer which can be used for selective treatment of nonmelanoma skin cancer. However, clinical research in this field is still scarce. Recently, sporadic trials have been conducted in wound healing, atopic dermatitis, psoriasis, and herpes simplex infections, partly with purified single constituents and modern dermatological formulations. St. John's wort also has a potential for use in medical skin care. Composition and stability of pharmaceutical formulations vary greatly depending on origin of the plant material, production method, lipophilicity of solvents, and storage conditions, and this must be regarded with respect to practical as well as scientific purposes.

Modern clinical research on the role of SJW in this field has been scarce compared to the numerous trials with oral forms in depression and other psychiatric indications. Consequently, the official 2009 HMPC monograph of the European Medicines Agency regards none of these applications as scientifically well established but accepts the use of topical SJW preparations for "symptomatic treatment of minor inflammations of the skin (such as sunburn) and as an aid in the healing of minor wounds" in the context of traditional medicine [4].

Increasing knowledge about pharmacological activities of SJW and its characteristic ingredients, such as hypericin and hyperforin, has given new impetus to investigate the potential of topical SJW preparations in dermatological problems of current interest. Anti-inflammatory, antimicrobial, and anticancer mechanisms as well as stimulation of tissue growth and differentiation have been reported for these compounds and suggest a potential benefit of using this old medicinal plant in skin diseases like atopic dermatitis, psoriasis, herpes infections, and white skin cancer, 


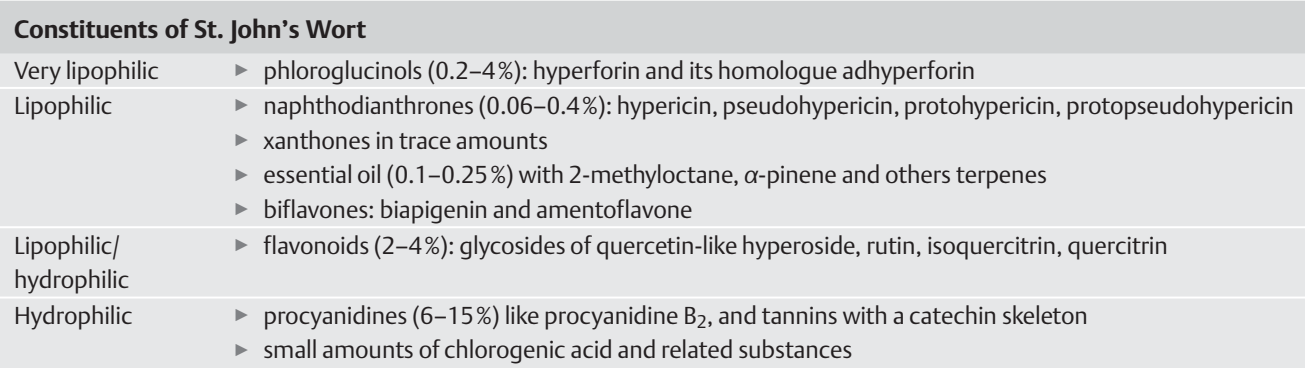

Table 1 Constituents of SJW with relevance for pharmacological activities.

Concentrations in brackets refer to the content in dried flowering tops; data from [12

and last not least in skin care. This review will focus on pharmacological mechanisms which are of special importance for dermatological indications, and on clinical data in the various fields of application.

\section{Traditional and Modern Topical Formulations, Content and Stability of Active Compounds \\ $\nabla$}

Constituents of SJW with pharmacological relevance are listed in - Table 1, and the structural formulas of the most important compounds are depicted in 0 Fig. 1. The actual concentrations of these constituents in topical preparations depend on many factors: geographic origin of the plant, harvest of wild cultivated plants, harvest time (there is a decrease in naphthodianthrones and an increase in phloroglucinols from flowering to fructification [5]), processing of fresh or dried plant material, lipophilicity and temperature of the extraction solvent and final formulation, exposure to sunlight, time and conditions of storing. Therefore, information on the specific preparation used in experiments or clinical trials is crucial for interpretation and reproducibility of data. This includes the method of production and, wherever possible, analytical data on the content and stability of the main active compounds.

The most commonly used topical preparation is Hypericum oil made from fresh or dried flowers or flowering aerial parts of the plant. For preparation of Oleum Hyperici [6], the plant material is doused (1:4) in vegetable oil (from olives, sunflowers, or others) in a white glass and kept in a warm place for fermentation. Thereafter the plant material is crushed, the oil filtered, and the aqueous phase removed with sodium sulfate, the glass sealed and exposed to sunlight for about 4-6 weeks; during this time, the oil takes on an intense ruby red color. The product is filled in a brown glass bottle for light protection but is, however, of limited stability.

While short exposure to visible light converts protohypericin to hypericin [7], this is degraded to further products when the exposure lasts for several weeks, and hypericin itself is contained in the finished oil at very low concentrations. The ruby red color of the finished oil is due to lipophilic breakdown products of hypericin [8].

The highly lipophilic phloroglucinol hyperforin is present at a concentration of $0.6 \%$ in fresh Hypericum oil produced in the light or dark but degrades to inactive compounds (furohyperforin, oxyhyperforin) within days under light exposure and within weeks under light protection; its stability can be increased to about 6 months by the addition of 2-octyldodecanol- 1 to the vegetable oil and under exclusion of oxygen $[5,8,9]$.

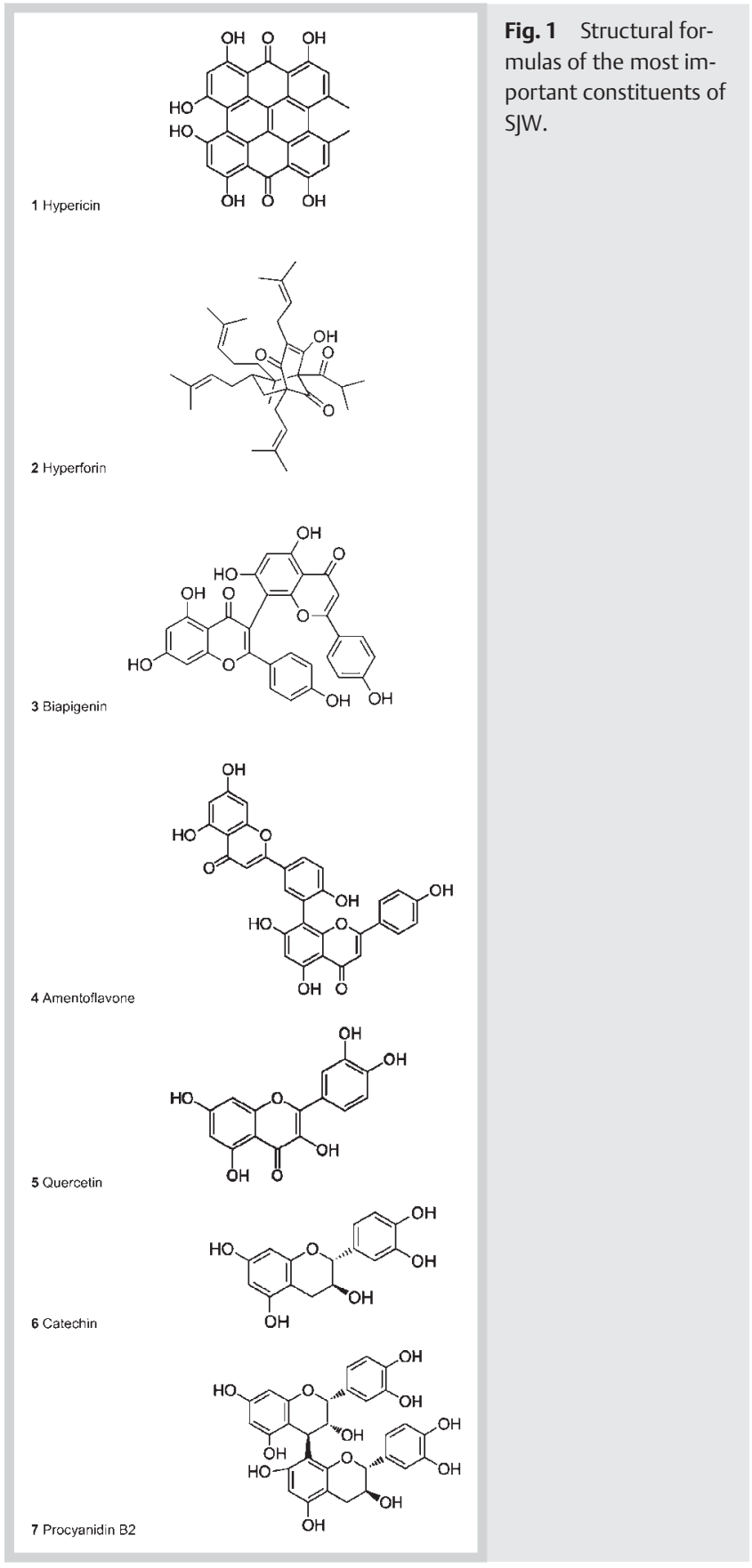


In order to obtain high concentrations of hyperforin, a potent antimicrobial and anti-inflammatory agent, Hypericum oil may be prepared from fruit capsules under light exclusion at room temperature and thereafter be stored in the dark at low temperatures. Alternatively, special stabilized hyperforin formulations may be used (see below).

The flavonoids quercetin, I3II8-biapigenin, kaempferol, und 1,3,6,7-tetrahydroxyxanthon were also reported for Hypericum oil [2,8], while Arsić et al. [10] found only quercetin and Isacchi et al. [5] merely the more lipophilic biflavone biapigenin, and this only when fresh flowers were extracted.

Orhan et al. [11] analyzed twenty-one samples of traditionallyprepared (homemade) and ready-made (commercial) SJW olive oil macerates by LC-DAD-MS. Pseudohypericin $(0.1-3.3 \mu \mathrm{g} / \mathrm{g})$ and hypericin $(0.3-6.6 \mu \mathrm{g} / \mathrm{g})$ were present in all the oils, whereas chlorogenic acid $(1.1 \mu \mathrm{g} / \mathrm{g})$ was detected only in one oil sample. Hyperforin was detected in four $(1-2.4 \mu \mathrm{g} / \mathrm{g})$ and adhyperforin in six samples $(0.005-3.2 \mu \mathrm{g} / \mathrm{g})$. All these concentrations are very low, in the range of $10^{-5}$ to $10^{-3} \%$. However, the authors correlated the antimicrobial activity against Staphylococcus aureus and Trypanosoma brucei with oil composition: hypericin and pseudohypericin were common in active oils whereas hyperforin, adhyperforin, and chlorogenic acid were absent.

Tinctures extracted with ethanol (45-50\%, drug: extract ratios $1: 5-10)$ are mentioned in the literature as traditional topical medicines, but details on their contents in active constituents as well as experimental data are missing [12]. Analyses of hydroalcoholic extracts from SJW revealed that at least $60 \%$ of ethanol concentrations are needed to obtain high yields of the very lipophilic hyperforin; with absolute ethanol, hyperforin extraction is maximal but hydrophilic components like flavonoids are greatly reduced [13].

More recently, various Hypericum formulations have been developed as gels, ointments, creams, lotions, sprays, and bath oils which may provide easier handling and higher stability than oils. Some were clinically tested and eventually marketed. However, declarations of marketed products are incomplete because they are not registered medical products, and relevant information about the composition, content of active components, and stability of investigational products is only given in a few publications. Kacerovská et al. [14] investigated the efficacy of SJW extract in photodynamic therapy (PDT) of nonmelanoma skin cancer with a viscous formulation consisting of $36 \%$ glycerol, $17 \%$ water, and $47 \%$ dry material of an ethanolic extract from dried material. The relevant compounds absorbing light at the wavelengths of the light source used were quantified in the final product as $0.15-$ $0.25 \%$ hypericin and pseudohypericin in a ratio of $1: 2$. According to the authors, the hypericins were stable under light protection at room temperature over 12 months. Tardivo et al. [15] used a $10 \%$ extract solution in ethylene glycol with $1 \%$ hypericin and $0.5 \%$ chlorophyll for phototreatment of herpes simplex. A lipophilic ointment with only $0.003 \%$ hypericin and $0.0024 \%$ hyperforin was able to protect human skin from solar-induced inflammation [16]. Extraction with liquid $\mathrm{CO}_{2}$ has been used to obtain very high (up to $30 \%$ ) concentrations of hyperforin; a cream containing an extract free of hypericin and flavonoids, but rich in hyperforin (1.5\% in the final product) was used by Schempp et al. [17] for the treatment of atopic dermatitis.

Taken together, there is a wide range of SJW formulations for topical treatment which may be adapted to the specific purpose, e.g., enriched in hypericin for PDT or in hyperforin for anti-inflammatory action. However, the production of formulations with repro- ducible and controlled contents of active compounds derived from plant material is still difficult. Synthetic components are sometimes used for better control, and modern nanoparticle and microvesicle formulations of SJW are under development.

\section{Pharmacological Mechanisms with Relevance for Topical Application \\ $\nabla$}

\section{Antimicrobial activity}

Methanol-acetone extracts from aerial parts of seven entities of the genus Hypericum growing in central Italy were tested in vitro for their antimicrobial activity. Two $H$. perforatum subspecies were particularly active against gram-positive and gram-negative bacteria. The results suggested that hypericin and hyperforin are the main components responsible for antimicrobial activity, but not the only ones [18]. Chloroform extracts of 34 Hypericum species and varieties were screened for activity against a clinical isolate of methicillin-resistant Staphylococcus aureus (MRSA), which in addition possessed a multidrug efflux mechanism conferring a high level of resistance to therapeutically useful antibiotics. Five extracts had minimum inhibitory concentrations of $64 \mu \mathrm{g} / \mathrm{mL}$ indicating potent activity against multidrug-resistant bacteria [19].

An antibacterial principle was isolated from Hypericum and named hyperforin [20]. Hyperforin inhibited growth in all tested gram-positive bacteria including MRSA and P(penicillin)RSA, with threshold concentrations from $0.1 \mu \mathrm{g} / \mathrm{mL}$ (Corynebacterium diphtheriae) to $1 \mu \mathrm{g} / \mathrm{mL}$, but not in gram-negative [21].

Antibacterial activity could also be attributed to hypericin. Growth of $S$. aureus but not $E$. coli was effectively stopped in vitro when incubated with hypericin concentrations from $40 \mu \mathrm{M}$ and below for $30 \mathrm{~min}$ and then irradiated with $5-30 \mathrm{~J} / \mathrm{cm}^{2}$ visible light of $600-800 \mathrm{~nm}$ wavelength; sensitivity of different bacterial species correlated with hypericin uptake, possibly reflecting the differences in membrane structure between gram-positive and gram-negative bacteria [22]. Gram-positive bacteria are generally more susceptible to Hypericum, but not all gram-negative species are resistant to hypericin plus light.

The antibacterial activity of SJW was higher when the herbs were collected in August compared to July [23], reflecting the increase in hyperforin content with fructification. Phloroglucinols and naphthodianthrones are the most important antibacterial components while flavonoids seem to be inactive [24]. Hence, lipophilic formulations are more effective than hydrophilic ones [25, 26 ]. The exact composition of oils and creams does, however, not seem to be very critical [10], and activity against gram-positive bacteria was even reported for hydrous SJW teas [27]. A comparison of SJW extract with its purified fractions containing hyperforin, hypericin, and pseudohypericin revealed that the extract inhibited growth of mycobacteria more effectively than the isolated components, indicating synergistic effects [28].

According to Peeva-Naumovska et al. [29] a lipophilic Hypericum ointment for vaginal application was active against a number of bacteria but not Lactobacillus acidophilus which is part of the natural vaginal flora. A detailed account of antibacterial activities of various Hypericum preparations is given by Saddiqe et al. [30] including ethnobotanical data on other species than $H$. perforatum. Antiviral activity of several Hypericum constituents against many forms of viruses in vitro has been demonstrated over the last 40 years, including herpes simplex virus types 1 and 2 [12]. Hypericin and some of its derivatives ("hypericins"), particularly when 
activated by light, are effective against enveloped viruses but not non-enveloped, probably by inhibiting budding of new virions, cross-linking of capsids preventing uncoating, inhibition of protein kinase required for viral replication, and inhibition of their ability to fuse with cell membranes [31,32].

Inhibition of protein kinase $\mathrm{C}$ during the viral infection of cells was also regarded as the mechanism underlying antiretroviral activity of hypericin and pseudohypericin [33]. Especially with regard to HIV, SJW and hypericins were intensively studied in systemic treatment, but concentrations needed clinically were so high that phototoxic effects became prohibitory [34]. Only recently, another SJW constituent, 3-hydroxy-lauric acid, was identified as a potent anti-HIV agent $[21,35]$, which may give new impetus to this field of research.

There is limited knowledge about the antifungal capacities of SJW in a dermatological context. While Schempp et al. [21] found no effect of hyperforin on Candida albicans in concentrations up to $100 \mu \mathrm{g} / \mathrm{mL}$, Arsić et al. [10] reported growth inhibition by SJW extract at $2.5 \mathrm{mg} / \mathrm{mL}$. It depends on the species-specific intracellular distribution of hypericin whether apoptotic pathways are triggered or not in different Candida species by irradiation with visible light [36]. Water extracts from Hypericum stopped the growth of Microsporum gypseum and Trichophyton rubrum at $10 \mathrm{mg} / \mathrm{mL}$ [37].

\section{Antioxidative activity}

Antioxidative properties of standardized hydroalcoholic SJW extracts have been found in vitro. In a cell free model and human vascular tissue, the effect of SJW on superoxide production by xanthine/xanthine oxidase was tested [38]. Both models demonstrated pro-oxidative effects at very high concentrations, and antioxidant effects inversely related to dose in a dilution series. At lower concentrations, standardized SJW extracts scavenged DPPH radicals in a dose-dependent manner; concentrations between 1 and $50 \mu \mathrm{g} / \mathrm{mL}$ effectively inhibited lipid peroxidation of rat brain cortex mitochondria induced by Fe2+/ascorbate or the NADPH system, and preincubation of human PC12 phaeochromocytoma cells with $1-100 \mu \mathrm{g} / \mathrm{mL}$ before exposure to superoxide attenuated caspase activity and reactive oxygen species generation, increasing cell survival [39]. Similarly, human neuroblastoma cells were protected from superoxide toxic action by preincubation with SJW extract [40].

The antioxidant effects of hydroalcoholic SJW extracts are not surprising since they contain up to $10 \%$ flavonoids which are well-known antioxidants. Polyphenol-rich Hypericum species all display pronounced antioxidant properties [41,42]. An SJW extract specifically enriched in flavonoids (quercetin and its derivatives) quenched DPPH with an $\mathrm{IC}_{50}=10.6 \mu \mathrm{g} / \mathrm{mL}$ and superoxide radical with an $\mathrm{IC}_{50}=54.3 \mu \mathrm{g} / \mathrm{mL}$ in a concentration-dependent manner. However, when higher amounts than $150 \mu \mathrm{g}$ of extract were added, the protective effect on lipid peroxidation was lost [43]. After all, the antioxidative capacities of SJW extract may switch to pro-oxidative at very high concentrations.

Besides the flavonoids, hyperforin has shown antioxidant properties in an $\mathrm{H}_{2}$ DCFDA assay in vitro with human HaCaT keratinocytes irradiated with solar-simulated radiation. The free radical scavenging capacity of hyperforin was higher with an $\mathrm{EC}_{50}=0.7 \mu \mathrm{M}(0.42 \mu \mathrm{g} / \mathrm{mL})$ than that of Trolox $(12 \mu \mathrm{g} / \mathrm{mL})$ and $\mathrm{N}-$ acetylcysteine $(847 \mu \mathrm{g} / \mathrm{mL})$; a cream containing hyperforin significantly protected porcine ear skin from reduced radical formation after solar radiation [44].

\section{Photosensitization}

While SJW exerts antioxidant action, it also contains components which can cause phototoxic cell damage. Onoue et al. [45] investigated 19 constituents from SJW and found that many of them are able to undergo photochemical reactions and produce reactive oxygen species, but only hypericin, pseudohypericin, and hyperforin caused lipid peroxidation, and none caused DNA strand breaks. Photoirritant potential of SJW is mainly attributable to the hypericins which absorb UVA at $300 \mathrm{~nm}$ and visible light in the range from 550 to $590 \mathrm{~nm}$. Treatment with hypericin and light irradiation produces singlet oxygen from the triplet state and superoxide from both the triplet state and semiquinone radical anion, followed by downstream formation of hydrogen peroxide.

Hypericins may cause severe photoxicity, e.g., in cattle grazing on SJW. It has however been shown that therapeutic oral doses of SJW extracts taken for treatment of mild to moderate depression do not cause photosensitization to a clinically relevant degree [46]. Traynor et al. [47] found only a very small effect on the genotoxic burden in HaCaT cells when hypericin treatment was combined with UVA irradiation in vitro and concluded that Hypericum intake, although reducing the minimal erythema dose measurably, would not constitute a problem in patients undergoing UVA phototherapy. Moreover, the phototoxic effects of hypericin on irradiated HaCaT keratinocytes are reduced by $25-50 \%$ when it is combined with other constituents of the SJW extract, e.g., chlorogenic acid, flavonoids, or pyropheophorbide [48].

Topical application of SJW extracts or isolated hypericin may cause photoirritation or phototoxicity depending on concentration and radiation intensity. This is an undesirable effect in wound healing or inflammation treatment but opens a new option in photodynamic therapy (PDT) of skin cancer or psoriasis, for example. Hypericin applied on mouse ears in concentrations from $0.1-1 \%$ resulted in limited phototoxicity only, probably due to confined penetration into the epidermal layers. However, hypericin acetate as a precursor penetrates easier and can cause more severe phototoxic damages than methyl aminolevulinic acid; phototoxicity of hypericin acetate declined within a few days after application, and induced wounds healed within 14 days [49].

Topical treatment with usual SJW formulations does not seem to have potential for severe photosensitization; the use of hypericins in PDT may be improved by specific formulations or derivatives increasing penetration into skin.

\section{Anti-inflammatory activity}

Anti-inflammatory effects of different SJW extracts and isolated constituents were investigated in the mouse ear model [50]. A lipophilic extract produced by supercritical carbon dioxide extraction from flowering SJW tops inhibited croton oil-induced swelling of the mouse ear more effectively than a hydroalcoholic extract and an ethylacetic fraction; of the pharmacologically active constituents, the lipophilic extract contained only hyperforin (27\%) and adhyperforin (5\%), while the other extracts displayed a variety of all relevant compounds but with lower concentrations of hyperforin ( $4.5 \%$ and $10.3 \%$, resp.). Among the isolated compounds tested, amentoflavone had the lowest 50\% inhibitory dose $\left(\mathrm{ID}_{50}=0.16 \mu \mathrm{mol} / \mathrm{cm}^{-2}\right)$, but this compound was not found in any of the extracts. Hypericin $\left(\mathrm{ID}_{50}=0.25 \mu \mathrm{mol} / \mathrm{cm}^{-2}\right)$, hyperforin in the form of its DHCA salt $\left(0.25 \mu \mathrm{M} / \mathrm{cm}^{-2}\right)$, and adhyperforin $\left(0.30 \mu \mathrm{mol} / \mathrm{cm}^{-2}\right)$ were also comparable to indomethacin $\left(0.26 \mu \mathrm{mol} / \mathrm{cm}^{-2}\right)$, while the flavonoids hyperoside and isoquer- 
cetin were less effective $\left(1 \mu \mathrm{mol} / \mathrm{cm}^{-2}\right)$. Given the high concentrations of the hyperforins in all extracts and their strong anti-inflammatory potency, they must be regarded as the most important anti-inflammatory components in SJW.

Hypericin significantly inhibited IL-12 production in lipopolysaccharide-activated mouse macrophages in a dose-dependent manner $\left(\mathrm{IC}_{50}=1.45 \mu \mathrm{g} / \mathrm{mL}\right)$ and the activation of the IL-12 gene promoter, suggesting that hypericin negatively regulated IL-12 production at the transcription level [51].

Anti-inflammatory mechanisms of hyperforin have been described as inhibition of cyclooxygenase-1 (but not COX-2) and 5lipoxygenase at low concentrations of $0.3 \mu \mathrm{mol} / \mathrm{L}$ and $1.2 \mu \mathrm{mol} / \mathrm{L}$, respectively [52], and of $\mathrm{PGE}_{2}$ production in vitro [53] and in vivo with superior efficiency $\left(\mathrm{ED}_{50}=1 \mathrm{mg} / \mathrm{kg}\right)$ compared to indomethacin $(5 \mathrm{mg} / \mathrm{kg})$ [54]. Hyperforin turned out to be a novel type of 5lipoxygenase inhibitor with high effectivity in vivo [55] and suppressed oxidative bursts in polymorphonuclear cells at $1.8 \mu \mathrm{mol} /$ L in vitro [56]. Inhibition of IFN- $\gamma$ production, strong downregulation of CXCR3 expression on activated T cells, and downregulation of matrix metalloproteinase 9 expression caused Cabrelle et al. [57] to test the effectivity of hyperforin in a rat model of experimental allergic encephalomyelitis (EAE). Hyperforin attenuated the symptoms significantly, and the authors discussed hyperforin as a putative therapeutic molecule for the treatment of autoimmune inflammatory diseases sustained by Th1 cells.

With specific reference to dermatological applications, Schempp et al. [58] investigated the alloantigen-presenting function of human epidermal cells (EC) exposed to Hypericum ointment containing $30 \mu \mathrm{g} / \mathrm{mL}$ hypericin and $24 \mu \mathrm{g} / \mathrm{mL}$ hyperforin in vivo in a mixed EC lymphocyte reaction (MECLR). Compared with untreated skin, treatment with Hypericum ointment resulted in a significant suppression of the MECLR $(\mathrm{p}<0.001)$ that was comparable to the effect of solar-simulated radiation. A similar effect was obtained when using an ointment with the same hyperforin content but devoid of hypericin. Epidermal cells isolated from hyperforin-treated skin showed a reduced capacity to stimulate the proliferation of allogeneic $\mathrm{T}$ cells $(\mathrm{p}<0.001)$, and in vitro incubation of EC with hyperforin suppressed the proliferation of alloreactive $T$ cells $(p<0.001)$. Furthermore, hyperforin inhibited the proliferation of peripheral blood mononuclear cells in a dose-dependent manner, without displaying pronounced toxic effects as determined by Trypan blue staining. The results provide a rationale for the traditional treatment of inflammatory skin disorders with Hypericum extracts containing hyperforin.

\section{Anticancer effects}

Pharmacological research has revealed two different fields in anticancer effects of SJW: light-dependent mechanisms related to photoactivation of the hypericins and light-independent mechanisms attributable to hyperforin.

Schempp et al. [59] investigated phototoxic and apoptose-inducing effects of pseudohypericin and hypericin in human leukemic lymphoma (Jurkat) cells and found dose-dependent inhibition of cell proliferation combined with DNA fragmentation under radiation with visible light from $520-750 \mathrm{~nm}$ wavelength, but not in dark. Hypericin was more effective than pseudohypericin ( $\mathrm{IC}_{50}$ $100 \mathrm{ng} / \mathrm{mL}$ vs. $200 \mathrm{ng} / \mathrm{mL}$ ). In the same model, photoactivated hypericin $(0.25-1 \mu \mathrm{g} / \mathrm{mL})$ was compared to $1 \mu \mathrm{g}$ of the cytostatic drug paclitaxel to elucidate the underlying mechanisms. Both photoactivated hypericins and paclitaxel similarly increased the activity of caspase- 8 and caspase-3, and drug-induced apoptosis of Jurkat cells was completely blocked by inhibitors of caspase- 8 and caspase-3. TRAIL antibody blocked TRAIL-induced and photo-induced hypericin, but not paclitaxel-induced apoptosis of Jurkat cells. In contrast, paclitaxel-induced but not hypericin-induced apoptosis was blocked by SM1/23 and NOK-2 antibodies. Anti-TNF-R1 antibody had no effect. These findings suggest that photo-induced hypericin apoptosis of Jurkat cells is mediated in part by the TRAIL/TRAIL-receptor system and subsequent activation of upstream caspases [60]. Sharma et al. [61] treated human squamous cell carcinoma cells in vitro with 1-7 $\mu \mathrm{M}$ hypericin photoactivated with $320-400 \mathrm{~nm}$ twice at $24 \mathrm{~h}$ intervals, resulting in greatly increased rates of cell death; the authors postulated a caspase-independent, rather necrotic than apoptotic mechanism of cell death. The same authors also treated human melanoma cell lines successfully with PDT in vitro when the cells had been incubated with kojic acid to inhibit melanin synthesis [62]. However, Menichini et al. [63] reported significant phototoxicity with $50 \%$ cell destruction in A375 human melanoma keratinocyte cells at a concentration of $78 \mu \mathrm{g} / \mathrm{mL}$ of a hydroalcoholic SJW extract and UV light even without pretreatment for melatonin destruction.

The lipophilic hypericin can enter cells by passive diffusion but is transported as LDL-hypericin complex when applied systemically. In glioma cells, photo-induced cell death processes are strongly influenced by the dynamics of hypericin subcellular redistribution processes involving monomer-aggregate equilibrium. Pharmaceutical formulations may potentially increase the efficacy of hypericin-PDT [64].

Cytotoxicity of photoactivated hypericin is higher than that of 5aminolevulinic acid, as its $\mathrm{LD}_{50}$ in medullablastoma cells was 813 times lower, with $0.47 \mathrm{~J} / \mathrm{cm}^{2}$ after $2 \mathrm{~h}$ exposure to $2.5 \mu \mathrm{M}$ hypericin [65]. The effect of photoactivated hypericin treatment in HT-29 colon adenoma cells was boosted by the addition of $5 \mu \mathrm{M}$ hyperforin or adhyperforin, resulting in apoptosis induction, inhibition of cell cycle progression, and expression of MMP-/-9 together with cell adhesivity, thereby affecting the clonogenic potential of the cells [66].

Currently, hypericin-PDT is intensively studied as a diagnostic and therapeutic tool for dermal and for internal cancer species.

Light-independent anticancer mechanisms of hyperforin were reported by Schempp et al. [67]. Hyperforin inhibited growth of tumor cells by induction of apoptosis. Hyperforin inhibited the growth of various rat and human (including squamous and melanoma) tumor cell lines in vitro, with $\mathrm{IC}_{50}$ values between $3 \pm 15 \mathrm{mM}$. In vivo, $2 \mathrm{mM}$ hyperforin inhibited the growth of autologous MT-450 breast carcinoma in immunocompetent Wistar rats to a similar extent as an equimolar dose of the cytotoxic drug paclitaxel, without any signs of acute toxicity. Treatment of tumor cells with hyperforin resulted in a dose-dependent generation of apoptosis-specific morphological changes and increased activity of caspase- 9 and caspase-3. In MT-450 cells, hyperforin, but not paclitaxel, induced a rapid loss of the mitochondrial transmembrane potential and subsequent morphological changes such as homogenization and vacuolization of mitochondria. Moreover, hyperforin was capable of releasing cytochrome $\mathrm{c}$ from isolated mitochondria, suggesting that hyperforin activates a mitochondria-mediated apoptosis pathway. This was confirmed by Merhi et al. [68] in acute myeloid leukemia (AML) cell lines defining distinct AML subfamilies and primary AML cells cultured ex vivo, demonstrating inhibition of Akt1 signaling, mitochondria, and Bcl-2 members dysfunctions, and activation of procaspases-9/-3 by hyperforin. In a further study, hyperforin induced apoptosis by 
triggering activation of caspases and hypericin synergistically exerted cytotoxicity towards human malignant cell lines [69].

Hyperforin also acts as an angiogenesis inhibitor by a direct, nontoxic effect on endothelial cells. In vitro, hyperforin blocked microvessel formation of human dermal microvascular endothelial cells on a complex extracellular matrix and reduced their proliferation in a dose-dependent manner, without displaying toxic effects or inducing apoptosis of the cells. In vivo, Wistar rats with subcutaneously injected MT-450 mammary carcinoma cells were treated with peritumoral injections of hyperforin or solvent. Hyperforin significantly inhibited tumor growth, induced apoptosis of tumor cells and reduced tumor vascularization [70].

The role of flavonoids, especially of quercetin and its derivatives, in the prevention and treatment of cancer has been extensively investigated $[71,72]$. However, they are more ubiquitous than the naphthodianthrones and phloroglucinols of Hypericum and play a minor role in lipophilic Hypericum formulations for dermal application.

\section{Wound repair and keratinocyte differentiation}

Mukherjee et al. [73] studied the effects of a methanolic leaf extract from Hypericum patulum in different rat wound models and found faster closure of excision wounds (comparable to $0.2 \%$ nitrofurazone) and higher tensile strength in incision wounds with the H. patulum extract, compared to control. Accordingly, Süntar et al. [74] confirmed significant acceleration of healing of excision, circular and linear incision wounds in rats when treated with $H$. perforatum oil extract and with ethanol extract applied in a mixture of glycol stearate, propylene glycol, and liquid paraffine $(3: 6: 1)$. When the ethanol extract was fractionated, the fraction containing hypericin as a major component was more effective than a flavonoid fraction. Castro et al. [75] found no difference in wound healing charateristics in rat models between microcurrent application alone and in combination with a homeopathic $10 \%$ (Hypericum D3) preparation; the SJW preparation alone was not effective, probably due to the low concentration. Öztürk et al. [76] investigated the effect of $1-100 \mu \mathrm{g} / \mathrm{mL}$ ethanolic SJW extract on embryonic chicken fibroblast cultures in comparison with dexpanthenol and Centella asiatica extract. The SJW extract contained small amounts of hypericin and pseudohypericin ( $0.1 \%$ each). With increasing SJW concentration, the total number of fibroblasts and the number of cells proliferating by mitosis increased, except for the highest concentration. The percentage of polygonal cells, indicating high motility, increased from $31 \%$ to $80 \%$, while the percentage of ageing, quiescent, and nonviable cells decreased, correspondingly. The number of collagen granules in the fibroblasts also increased. Quantitative comparison of the effects of the 3 test substances showed that both herbal extracts could promote wound repair rather by stimulation of collagen production and fibroblasts migration than by increasing mitotic cell proliferation, as is characteristic for dexpanthenol. Hostanska et al. [77] reported similar results for a homeopathic preparation containing SJW, but also marigold, arnica, and comfrey, so that the contribution of SJW cannot be determined.

The effect of SJW is not restricted to the proliferative phase of wound healing but also improves functional organization of the epidermis when newly established after injury or when functionally impaired by diseases like atopic dermatitis and psoriasis [78]. Incomplete formation of the upper epidermal layers leads to increased trans-epidermal water loss, microbial infections, inflammation, and itching. Besides its antimicrobial and anti-inflammatory activity, hyperforin is able to restore impaired epi- dermal organization by stimulating keratinocyte differentiation and formation of the "cornified envelop". Differentiation of keratinocytes is promoted by activation of the specific transient receptor potential channel (TRPC6, an effect also involved in the antidepressive activity of hyperforin) in much the same way as an increase of the physiological stimulus, extracellular calcium concentration [79]. Since TRP receptors seem also to be related to itching, hyperforin might be a multitarget dermatological pharmacon (๑ Fig. 2).

A $1 \%$ chlorogenic acid ointment had a similar effectiveness in rat full-thickness excision wound healing as a $1 \%$ silver sulfadiazine ointment when applied topically once a day for 15 days. Chlorogenic acid increased rates of epithelialization, cellular proliferation, TNF- $\alpha$ levels during the inflammatory phase of wound healing, TGF- $\beta 1$, and collagen IV synthesis, and had potent antioxidant activity by increasing superoxide dismutase, catalase, and glutathione, and decreasing lipid peroxidation [80]. Thus, a number of different SJW constituents are involved in wound healing, but the amounts of chlorogenic acid may be too low to contribute substantially.

\section{Clinical Experience}

$\nabla$

A short reference is made at the beginning of each section to the pharmacological mechanisms justifying clinical research in the respective indication. Clinical data are classified for the level of evidence (= LOE) [81] wherever this seemed meaningful to do.

\section{Wound healing}

The clinical rationale for SJW treatment of wounds results from its antimicrobial and anti-inflammatory activities, and from stimulation of fibroblast motility, collagen production, and keratinocyte differentiation. Oils and other formulations containing hyperforin and hypericin or their derivatives are appropriate for application on scratches, abrasions, burns, and ulcers. Although blunt traumata like contusions and myalgia are mentioned as traditional indications [2], no studies have been performed in these indications with topical formulations, but some data is available for burns, decubitus, and surgical wounds.

A burn ointment prepared by extracting $5 \mathrm{~g}$ of fresh flowers with $100 \mathrm{~g}$ of olive oil for 10 days at $20^{\circ} \mathrm{C}$ was used in the treatment of 1 st, 2nd, and 3rd degree burns. First degree burns healed within 48 hours. Second and third degree burns healed at least 3 times as rapidly as burns treated with conventional methods, and keloid formation was inhibited ([82] LOE: 4).

SJW oil made from plants collected in Italy in June and July was tested for its effect on lower back bedsores (decubitus) in $30 \mathrm{pa}-$ tients. $350 \mathrm{~g}$ of crashed flowering tops were extracted for 1 hour in $1000 \mathrm{~mL}$ olive oil until taking on a red color, filtrated and sterilized at $120 \mathrm{~min}$ for 1 hour. Fifteen patients were treated twice a day with disinfection with oxygenized water, a layer of sterile gaze impregnated with Hypericum oil directly applied on the wound, another sterile gaze layer and occlusive Leukoflex foil. The other half of the patients was treated the same way but with pure olive oil for control. The treatment continued for 15 days. Total (weeping) wound area was determined by applying blotting paper soaked with $5 \%$ potassium permanganate, the area of deep wounds were depicted by using a metallic probe and a metric frame allowing to localize spots with $>5 \mathrm{~mm}$ deepness, which were connected on a chart. In the treatment group, the total wound area was reduced by $37.6 \%$ from $109 \pm 29 \mathrm{~cm}^{-2}$ to 


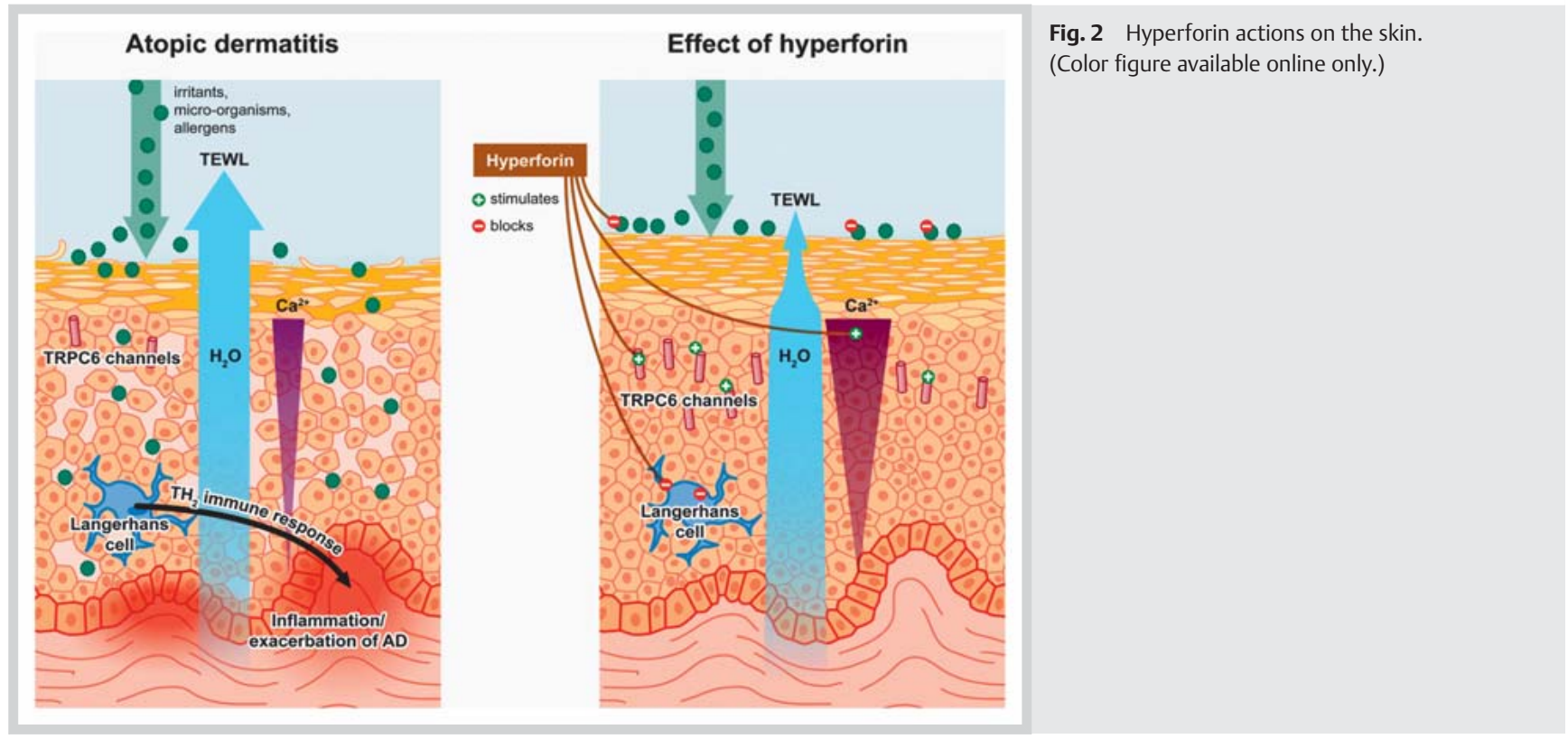

$69 \pm 23 \mathrm{~cm}^{-2}$, while in the control group the reduction was only $17 \%\left(123 \pm 29 \mathrm{~cm}^{-2}\right.$ to $\left.94 \pm 24 \mathrm{~cm}^{-2}\right)$. The deep area was reduced by $37 \%$ with SJW oil, in contrast to only $12 \%$ in the control group. Differences between groups were $\mathrm{p}<0.001$ for both efficacy criteria ([83] LOE: 2b).

The effects of an ointment containing extracts of garlic, calendula and SJW (70\% ethanol, DER 5: 1, 0.1\% hypericin, 3.1\% flavonoids) on venous ulcers (ulcus cruris venosum) were tested over a 7week period in 25 patients with ulceration of the lower leg no longer than 2 months, or recurrent ulceration during the last 6 months. The patients did not use any other phytomedicines or supportive therapies. The total treatment response was evaluated on the basis of epithelialization, granulation, fibrin deposits, exudation, and edema. Reporting of results is somewhat contradictory; however, epithelialization improved with a mean reduction of the ulcer area by $55 \%$. No significant effects on the microbial flora were found. Since there was no control and the ointment contained a fix combination of herbs, the effect of SJW on ulcers cannot be estimated from these data [84].

Similarly, a clinical study on wound closure in 12 patients after cesarean section who were treated with a combination of calendula and SJW in wheat germ oil (the SJW oil prepared as described by Lomagno and Lomagno [83], see above) twice a day for 15 days cannot be interpreted with respect to the contribution by SJW; the preparation accelerated wound healing compared to control treatment with wheat germ oil, with $38 \%$ vs. $16 \%$ reduction of the wound area [85].

A randomized, double-blind clinical trial on the effect of an oily SJW ointment in cesarean section wound healing and hypertrophic scar included 144 women randomly assigned to three groups. The treatment and placebo groups applied SJW (V) or placebo (P) ointment 3 times a day for 16 days, the control (C) group remained without any intervention postoperatively. The SJW formulation was prepared by drying and crushing of flowering SJW tops and maceration in grape seed oil (1:3), heating in a microwave oven for $15 \mathrm{~min}$, filtration with a $0.45-\mathrm{mm}$ membrane filter, and mixing (1:4) with sterilized petroleum jelly. Wound healing was assessed on the 10th day post-cesarean using the REEDA (redness, edema, ecchymosis, discharge, and approxima- tion) scale. On the 40th day, the degree of scarring was assessed using the Vancouver scar scale including pigmentation, height, pliability, and vascularity. The subjects were also asked some questions about pain by using the visual analogue scale and pruritus of scar. The mean age of all the study subjects was $23.5 \pm 4.0$ years and mean parity was $1.2 \pm 0.5$. There were significant differences in wound healing on the 10th day with REEDA scores of $0.19(\mathrm{~V}), 0.75(\mathrm{P})$, and $0.79(\mathrm{C})$, respectively $(\mathrm{p}<0.005)$, and scar formation on the 40th day postpartum with Vancouver scores of $3.3(\mathrm{~V}), 5.0(\mathrm{P})$, and $5.5(\mathrm{C})(\mathrm{p}<0.0001)$ between the treatment group compared with placebo and control groups. However, the placebo group had no differences in wound healing $(\mathrm{p}=0.93)$ and scar formation ( $\mathrm{p}=0.11$ ) from the control group. In addition, significantly lower pain and pruritus were reported by the treatment group compared with the placebo and control groups on the 40th day postpartum. This study confirms practical experience that cicatrization of surgical wounds is positively influenced by SJW treatment ([86] LOE: 1b).

A wound dressing with a mixture of SJW oil and neem oil was investigated for wound healing effects in a retrospective review of 9 patients presenting with scalp wounds with exposed bone following the excision of skin tumors and treated with the commercial plant-derived wound dressing at a dermatology department of a university hospital in Switzerland. Time to healing, wound size, area of exposed bone, ease of handling, pain, and complications were evaluated. The patients' mean age was 81 years, with a mean wound size of $13.2 \mathrm{~cm}^{-2}$ and $6.8 \mathrm{~cm}^{-2}$ of exposed bone. The time to complete healing by secondary intention was 4-20 weeks. A rapid induction of granulation tissue was observed, which covered the entire exposed bone surface in six out of nine cases (67\%) after 4 weeks, and showed a reduction in the mean area of exposed bone of $95 \%$. Dressing change was easy and without pain, and there were no complications. Composition of the formulation is not described in detail, and the efficacy of SJW cannot be assessed due to the use of a combination product and missing control [87]. 


\section{Atopic dermatitis}

Atopic skin is characterized by inflammation, hypersensitivity to irritant stimuli, itching and consequently scratching and smaller epidermal lesions, impaired skin barrier associated with transdermal water loss, weeping, and bacterial infection. Helpful pharmacological mechanisms are therefore anti-inflammatory and antibacterial activity, stimulation of keratinocyte differentiation, and soothing of itches. SJW extract seems quite appropriate to match these requests; however, application of herbal extracts with numerous constituents onto atopic skin also involves a risk of further sensitization.

Hyperforin was shown to fulfill the listed requirements directly (or indirectly with regard to itching) as demonstrated above, without potential photosensitization; this gave the idea to conduct a clinical study on the effect of a cream containing flavonoids and hypericin below the detection level but enriched in hyperforin, in patients with atopic dermatitis. In the prospective, randomized, placebo-controlled, double-blind, monocentric half-side comparison study, the efficacy of a cream containing $1.5 \%$ hyperforin (verum) was assessed in comparison to the corresponding vehicle (placebo) for the treatment of subacute atopic dermatitis. Vehicle composition (INCI) was aqua, petrolatum, propylene glycol, caprylic/capric triglyceride, PEG-20 glyceryl stearate, panthenol, phenoxyethanol, Hypericum perforatum extract, tocopherol, tocopheryl acetate, and allantoin. In twentyone patients suffering from mild to moderate atopic dermatitis (mean SCORAD 44.5), the treatment with verum or placebo was randomly allocated to the left or right side of the body, respectively. The patients were treated twice daily over a period of four weeks. Eighteen patients completed the study. The severity of the skin lesions on the left and right side was determined by means of a modified SCORAD index (primary endpoint). The intensity of the eczematous lesions improved on both sites of treatment. However, the Hypericum cream was significantly superior to the vehicle at all clinical visits (days $7,14,28)(\mathrm{p}<0.05)$. Skin colonization with Staphylococcus aureus was reduced by both verum and placebo, showing a trend to better antibacterial activity of the Hypericum cream ( $\mathrm{p}=0.064)$. Skin tolerance and cosmetic acceptability was good or excellent with both the Hypericum cream and the vehicle (secondary endpoints).

Taken together, the study showed a significant superiority of the Hypericum cream compared to the vehicle in the topical treatment of mild to moderate atopic dermatitis. The therapeutic efficacy of the Hypericum cream, however, has to be evaluated in further studies with larger patient cohorts, in comparison to therapeutic standards, i.e., glucocorticoids ([17] LOE: 2b).

\section{Psoriasis}

From the histological point of view, psoriatic plaques have three key charateristics: the extravagant growth of keratinocytes; the presence of prominent, dilated dermal blood vessels and an inflammatory infiltrate, featuring $\mathrm{T}$ cells of several subtypes, along with neutrophils and macrophages. As has become clear in recent years, this $\mathrm{T}$ cell-driven inflammation is responsible for the keratinocyte growth and the angiogenesis seen in psoriatic plaques [88].

SJW, and especially hyperforin, displays anti-inflammatory activity on $\mathrm{T}$ cells and stimulation of keratinocyte differentiation. In a case series, ten patients with plaque-type psoriasis were treated with SJW ointment; unfortunately, no specifics are reported on the nature of the extract except that it was quite pure. The Hypericum ointment was applied to one side of each patient's body and the vehicle to the opposite side twice daily for 4 weeks in a singleblinded manner. Modified psoriasis area severity index (PASI) scores were significantly lowered where the formulated ointment had been applied. In determining PASI scores, three factors, erythema, scaling, and thickness, were evaluated; all were significantly lower where the formulated ointment had been applied $(\mathrm{p}=0.01, \mathrm{p}=0.004, \mathrm{p}=0.04)$, with initial scores from 2.1-2.6 and final scores from 1.8-2.1 for placebo and $0.7-1.1$ for verum. SJW ointment applied twice daily may be effective in reducing PASI scores in mild plaque-type psoriasis, however, further larger studies need be conducted to achieve a more conclusive result ([88] LOE: 4).

Since photodynamic therapy (PDT) is also used as a treatment for psoriasis, a combination with SJW or purified/synthetic hypericins might also be an option, but clinical evidence is still missing.

\section{Herpes simplex}

Treatment of herpes simplex with SJW makes use of the ability of hypericins to inhibit protein kinase $C$ and thus suppress viral replication, especially when combined with UV or visible light. However, clinical efficacy against herpes simplex 1 and 2 (herpes labialis and genitalis) has also been reported for oral administration of $900-1800 \mathrm{mg}$ of a $70 \%$ ethanolic SJW extract as used in treatment of depression. Two independent double-blind, randomized, placebo-controlled studies with 94 and 110 patients, respectively, demonstrated highly significant differences in symptom scores (subjective symptoms like pain and itching, number of blisters, and size of affected area). Unfortunately, the results have only been published in abstract form ([89] LOE: $2 b$ ).

A topical formulation combining SJW ("0.1\% Hypericum perforatum", no further details provided) with $5 \%$ copper sulfate, Calendula, and Aloe was compared to a $5 \%$ aciclovir preparation in a randomized, open-label multicenter study with 149 patients suffering from herpes simplex 1 or 2 . Under 14-day treatment, the odds for being affected by a burning and stinging sensation were 1.9 times greater in the aciclovir group, with similar results for acute pain (1.8), erythema (2.4), and vesiculation (4.4). The contribution of SJW to the effect of the formulation remains unclear [90]. Topical photodynamic treatment of herpes infections is being investigated in an ambulatory clinic in São Paulo, Brazil, since several years, by local injection either of methylene blue or SJW (10\% in ethylene glycol, containing $1 \%$ hypericin and $0.5 \%$ chlorophyll) as a photosensitizer for radiation with visible light, maximum at $650 \mathrm{~nm}$. Both photosensitizers reduced the recurrence rate of herpes exacerbations from about 10 to 5 per year; no exact numbers or details are reported with reference to the ongoing study; post-treatment cosmesis was excellent ([15] LOE: 5).

\section{Solar keratoses and non-melanoma skin cancer}

Photodynamic therapy (PDT) makes use of the fact that tumor cells have much higher metabolic activity and may enrich certain phototoxic substances which then are irradiated with an appropriate wavelength to kill the cells. Like 5-aminolevulinic acid, a standard photosensitizer for treatment of nonmelanoma skin cancer, hypericin is enriched in tumor cells and activated by visible light which is harmless to normal cells, but hypericin is much more cytotoxic in vitro than 5-aminolevulinic acid.

In a clinical study, 8 patients with squamous cell carcinoma (SCC) and 11 patients with basal cell carcinoma (BCC) were treated by local injection of hypericin and irradiation with visible light. Patients with SCC were given 40-100 $\mu$ g hypericin intralesionally, 
3-5 times per week for 2-4 weeks; patients with BCC 40-200 $\mu \mathrm{g}$ hypericin 3-5 times per week for 2-6 weeks. Hypericin displayed selective tumor-targeting: penetration in the surrounding tissues did not induce necrosis or cell loss and even the generation of a new epithelium at the surface of the malignancy was noticed. Clinical remissions were found after 6-8 weeks ([91] LOE: 4).

A prospective study on the efficacy of PDT with topical application of a SJW extract in actinic keratoses (AK), basal cell carcinoma (BCC), and Morbus Bowen (carcinoma in situ) was carried out on 34 patients -8 with AK, 21 with BCC, and 5 with Bowen's disease [14]. A viscous formulation consisting of $36 \%$ glycerol, $17 \%$ water, and $47 \%$ dry ethanolic extract with $0.15-0.25 \%$ hypericin and pseudohypericin in a ratio of $1: 2$ was applied on the skin lesions under occlusion for $2 \mathrm{~h}$ and then irradiated with $75 \mathrm{~J} \cdot \mathrm{cm}^{-2}$ of red light. The treatment was performed weekly for 6 weeks on average. The percentage of complete clinical response was $50 \%$ for AK, $28 \%$ in patients with superficial BCC, and $40 \%$ in patients with Bowen's disease. There was only a partial remission seen in patients with nodular BCCs. A complete disappearance of tumor cells was found in the histologic preparation of $11 \%$ of patients with superficial BCCs and $80 \%$ in the patients with Bowen's disease. All patients complained of burning and pain sensations during irradiation, which is, however, normal in PDT. Although the results of this first clinical trial could be regarded as disappointing - recent studies with 5-aminolevulinic acid, a precursor of protoporphyrin IX and standard sensitizer PDT of AK, showed complete clearance rates up to $80 \%$ after 1 to 2 treatments only [92] - there are still possibilities for improvement. Better preparation of the lesions, enhancement of hypericin delivery, use of better penetrating derivatives such as hypericin acetate and other types of light exposure procedures could significantly improve the clinical outcomes of this relatively inexpensive treatment modality ([14] LOE: 2b).

\section{Skin care}

Dry skin and or skin stressed by professional exposition to detergents often is substrate for microbial infections, inflammation, and itching. An important function of skin care products is to reinforce the skin barrier against water loss. Hyperforin with its effect of keratinocyte differentiation may help to reduce transepidermal water loss, and several constituents of SJW have antimicrobial and anti-inflammatory activities.

Arsić et al. [10] formulated three $\mathrm{O} / \mathrm{W}$ creams containing $15 \%(\mathrm{w} /$ v) of SJW oil extract, produced according to traditional prescriptions, as an active ingredient, however with different vegetable (olive, palm, and sunflower) oils. The investigated $\mathrm{O} / \mathrm{W}$ creams demonstrated significant anti-inflammatory effects in a doubleblind randomized study with 20 healthy volunteers, using a sodium lauryl sulphate test. Both skin parameters assessed in the study (electrical capacitance and erythema index) were restored to the baseline value after a seven-day treatment with the tested creams.

In a 4-week use trial with 15 adult atopic patients after treatment with hyperforin cream, an increase in hydration, as well as a reduction of TEWL and scaliness, was observed as opposed to the vehicle control [93].

The formation of radicals plays an important role in the development of atopic eczema or barrier-disrupted skin. Arndt et al. [94, 95] evaluated the radical scavenging effect of a cream containing an SJW extract rich in hyperforin in a double-blind placebo-controlled study on 11 healthy volunteers. Electron paramagnetic resonance spectroscopy was applied to determine radical forma- tion during VIS/NIR irradiation of the inner forearm. The results were compared to ex vivo investigations on excised porcine ear skin after a single application of the creams. The non-treated skin was measured as a control. The absolute values and the kinetics were not comparable for ex vivo and in vivo radical formation. Whereas in in vivo, the radical production decreased with time, it remained stable ex vivo over the investigated timescale. Nevertheless, ex vivo methods could be developed to estimate the protection efficiency of creams. In in vivo as well as ex vivo, the radical formation could be reduced by almost $80 \%$ when applying the hyperforin-rich cream onto the skin, whereas placebo resulted in about $60 \%$. In in vivo, a daylong protection effect could be validated after a 4-week application time of the cream indicating that a regular application is necessary to obtain the full effect. Clinically, the skin lipids in both verum and placebo groups increased directly after a single cream application but only significantly for ceramide [AP], [NP1], and squalene.

\section{Safety and tolerability of dermal application}

SJW is one of the best investigated herbal medicines, with respect to efficacy as well as toxicology and safety. Acute toxicity studies using rats, guinea pigs, and mice indicate that the extract is relatively nontoxic and does not present a risk to patients. A weak positive outcome of tests on mutagenicity of ethanolic extracts in the AMES test can be explained with the presence of quercetin which is not genotoxic in vivo in the extracts. In several in vivo (mammalian spot test in mice, chromosome aberration test in Chinese hamsters) and in vitro test systems (HGPRT test, UDS unscheduled DNA synthesis test, cell transformation test), no signs of a mutagenic potential could be detected $[12,96]$. Clinically relevant interactions of hyperforin with other drugs can be excluded when topically applied, due to the very low plasma concentrations.

Potential adverse effects of dermal application may be irritation/ sensitization and unwanted photosensitization, although clinical data available suggests that the risk is relatively low. In an irritation test, $50 \mu \mathrm{L}$ per test area of a bath oil containing SJW extract was administered to the volar surface of the arm in 18 volunteers under occlusion for $24 \mathrm{~h}$. After an hour, the test areas were evaluated; the test substance was readministered for another $24 \mathrm{~h}$, and the skin areas were evaluated again for transepidermal water loss (TEWL), photometric measurements of skin erythema, and visual scoring. The bath oil did not cause irritation and was similar to the control of distilled water [97]. Topical application of SJW oil (with $110 \mu \mathrm{g} / \mathrm{mL}$ hypericin) or SJW ointment $(30 \mu \mathrm{g} / \mathrm{mL}$ ) on the forearms of volunteers and solar simulated radiation resulted in no or only mild photosensitization, respectively [16]. Despite the low phototoxic potential of topical hypericin treatment, cautious application of traditional SJW extracts seems to be necessary since higher penetration rates of hypericin may occur in lesional skin. Furthermore, in fair-skinned individuals and after extended solar irradiation, increased susceptibility to the photosensitizing properties of hypericin-containing preparations may occur.

\section{Conclusions}

$\nabla$

Although SJW contains a broad spectrum of pharmacologically active substances, two chemical classes appear as the most interesting for dermatological applications: the phloroglucinols (hyperforins) and the naphthodianthrones (hypericins). Hyperforins 
have potent antimicrobial, antioxidant, anti-inflammatory, and anticancer effects and stimulate growth and differentiation of keratinocytes. Hypericins also show antimicrobial, anti-inflammatory, and anticancer activities, especially when irradiated with visible light, and their photo-induced cytotoxicity can be used for photodynamic treatment of non-melanoma skin cancer but also for diagnostic purposes. There are some indications for synergistic activity of hyperforins and hypericins, as well as other constituents such as flavonoids and biflavones, which may explain why traditional preparations seem to have robust effectivity in spite of their variable composition. For specific therapeutic purposes, however, it may be favorable to use purified special extracts with one or two of the major components. Most important is, in any case, to conduct all pharmacological and clinical investigations with well-defined and stable formulations and to describe their preparation and composition in detail in the publications.

A plethora of pharmacological investigations presents a rationale for the use of SJW in the traditional indications, and Hypericum oil can still be recommended as an integral part of the medicine chest for treatment of abrasions, burns, and sunburns. However, only a few clinical trials have been conducted which allow an estimation of its therapeutic value in nontrivial applications relative to other treatments, for example, in wound healing, atopic dermatitis psoriasis, and nonmelanoma skin cancer. Hyperforin may have potential for treatment of inflammatory skin diseases with autoimmune deficiencies. Hypericin could be further developed into a potent and valuable sensitizer for PDT of skin cancer. Other indications where inflammation and microbial infection present problems to sensitive skin should be explored.

\section{Conflict of Interest}

$\nabla$

The authors declare that they have no conflict of interest.

\section{References}

1 Pliny the Elder (23-79 A.D.). The natural history. Book XXVI, Chapter LXXX. Cited after: Bostock J, Riley HT, editors. London: Taylor and Francis; 1855. The perseus digital library. Available at: http://www.perseus. tufts.edu/hopper/text?doc=Perseus\%3atext\%3a1999.02.0137. Accessed April 5, 2013

2 Blaschek W, Ebel S, Hackenthal E, Holzgrabe U, Keller K, Reichling J, Schulz V. Hagers Handbuch der pharmazeutischen Praxis. Berlin, Heidelberg: Springer Verlag; 2008

3 WHO WHO-Monographs on selected medical plants. Geneva: World Health Organization; 2002

4 EMEA (European Medicines Agency). HMPC Community herbal monograph on Hypericum perforatum L., herba (Traditional use). EMEA/ HMPC/745582/2009. Wien Med Wochenschr 2010; 160: 557-563

5 Isacchi B, Bergonzi MC, Carnevali F, van der Esch SA, Vincieri FF, Bilia AR. Analysis and stability of the constituents of St. John's wort oils prepared with different methods. J Pharm Biomed Anal 2007; 45: 756761

6 German Pharmacopoeia, EB6 (Deutsches Arzneibuch. Suppl., 6th edition). Bonn: Phytopharmaceutical Corporation; 1941: 409

7 Schmidt $A H$. Use of an on-line, precolumn photochemical reactor in high-performance liquid chromatography of naphthodianthrones in Hypericum perforatum preparations. J Chromatogr A 2003; 987: 181187

8 Maisenbacher P, Kovar KA. Analysis and stability of Hyperici oleum. Planta Med 1992; 58: 351-354

9 Verotta L, Appendino G, Jakupovic J, Bombardelli E. Hyperforin analogues from St. John's wort (Hypericum perforatum). J Nat Prod 2000; 63: $412-415$

10 Arsić I, Zugić A, Tadić V, Tasić-Kostov M, Mišić D, Primorac M, RunjaićAntić $D$. Estimation of dermatological application of creams with St. John's Wort oil extracts. Molecules 2011; 17: 275-294
11 Orhan IE, Kartal M, Gülpinar AR, Cos P, Matheeussen A, Maes L, Tasdemir $D$. Assessment of antimicrobial and antiprotozoal activity of the olive oil macerate samples of Hypericum perforatum and their LC-DAD-MS analyses. Food Chem 2013; 138: 870-875

12 EMEA (European Medicines Agency). HMPC assessment report on $\mathrm{Hy}$ pericum perforatum L., Herba. EMA/HMPC/101303/2008. London: EMEA; 2009

13 Gaedcke F. Herstell- und Qualitätsaspekte pflanzlicher Extrakte. Pharmazie in unserer Zeit 2003; 3: 192-202

14 Kacerovská D, Pizinger K, Majer F, Smíd F. Photodynamic therapy of nonmelanoma skin cancer with topical Hypericum perforatum extract-a pilot study. Photochem Photobiol 2008; 84: 779-785

15 Tardivo JP, Wainwright M, Baptista MS. Local clinical phototreatment of herpes infection in São Paulo. Photodiagnosis Photodyn Ther 2012; 9: 118-121

16 Schempp CM, Lüdtke R, Winghofer B, Simon JC. Effect of topical application of Hypericum perforatum extract (St. John's wort) on skin sensitivity to solar simulated radiation. Photodermatol Photoimmunol Photomed 2000; 16: 125-128

17 Schempp CM, Windeck T, Hezel S, Simon JC. Topical treatment of atopic dermatitis with St. John's wort cream - a randomized, placebo controlled, double blind half-side comparison. Phytomedicine 2003; 10 (Suppl. 4): 31-37

18 Cecchini C, Cresci A, Coman MM, Ricciutelli M, Sagratini G, Vittori S, Lucarini D, Maggi F. Antimicrobial activity of seven Hypericum entities from central Italy. Planta Med 2007; 73: 564-566

19 Gibbons S, Ohlendorf B, Johnsen I. The genus Hypericum - a valuable resource of anti-Staphylococcal leads. Fitoterapia 2002; 73: 300-304

20 Bystrov NS, Dobrynin VN, Kolosov MN, Chernov BK, Chervin II. [Structure of the chromophoric part of hyperforin]. Dokl Akad Nauk SSSR 1975; 225: $1327-1328$

21 Schempp CM, Pelz K, Wittmer A, Schöpf E, Simon JC. Antibacterial activity of hyperforin from St John's wort, against multiresistant Staphylococcus aureus and gram-positive bacteria. Lancet 1999; 353: 2129

22 Yow CM, Tang HM, Chu ES, Huang Z. Hypericin-mediated photodynamic antimicrobial effect on clinically isolated pathogens. Photochem Photobiol 2012; 88: 626-632

23 Borchardt JR, Wyse DL, Sheaffer CC, Kauppi KL, Fulcher RG, Ehlke NG, Bicsboer DD, Bey RF. Antimicrobial activity of native and naturalized plants of Minnesota and Wisconsin. J Med Plants Res 2008; 2: 98-110

24 Avato P, Raffo F, Guglielmi G, Vitali C, Rosato A. Extracts from St John's Wort and their antimicrobial activity. Phytother Res 2004; 18: 230232

25 Dadgar T, Asmar M, Saifi A, Mazandarani M, Bayat H, Moradi A, Bazueri $M$, Ghaemi E. Antibacterial activity of certain medicinal plants against methicillin resistant and methicillin sensitive Staphylococcus aureus. Asian J Plant Sci 2006; 5: 861-866

26 Lasik M, Nowak J, Stachowiak B, Czarnecki Z. Evaluation of the antagonistic properties of natural antibacterial substances extracted from herbs: poster presentation. Eurobiotech 2007; 54: 10 (cited after Saddiqe 2010)

27 Reichling J, Weseler A, Saller R. A current review of the antimicrobial activity of Hypericum perforatum L. Pharmacopsychiatry 2001; 34 (Suppl. 1): S116-S118

28 Mortensen T, Shen S, Shen F, Walsh MK, Sims RC, Miller CD. Investigating the effectiveness of St John's wort herb as an antimicrobial agent against Mycobacteria. Phytother Res 2012; 26: 1327-1333

29 Peeva-Naumovska V, Panovski N, Grdanovska T, Fredro-Kumbaradzi E. Formulations of St. John's Wort oil ointment and evaluation of its antibacterial effect. Available at www.amapseec.org/cmapseec.1/papers/ pap-p067.htm 2000. Accessed April 28, 2013

30 Saddiqe Z, Naeem I, Maimoona A. A review of the antibacterial activity of Hypericum perforatum L. J Ethnopharmacol 2010; 131: 511-521

31 Birt DF, Widrlechner MP, Hammer KD, Hillwig ML, Wei J, Kraus GA, Murphy PA, McCoy J, Wurtele ES, Neighbors JD, Wiemer DF, Maury WJ, Price $J P$. Hypericum in infection: Identification of anti-viral and anti-inflammatory constituents. Pharm Biol 2009; 47: 774-782

32 Klemow KM, Bartlow A, Crawford J, Kocher N, Shah J, Ritsick M. Medical attributes of St. John's Wort (Hypericum perforatum). In: Benzie IFF, Wachtel-Galor S, editors. Herbal medicine: biomolecular and clinical aspects, 2nd edition. Boca Raton: CRC Press; 2011 (Chapter 11)

33 Takahashi I, Nakanishi S, Kobayashi E, Nakano H, Suzuki K, Tamaoki T. Hypericin and pseudohypericin specifically inhibit protein kinase C: possible relation to their antiretroviral activity. Biochem Biophys Res Commun 1989; 165: 1207-1212 
34 Gulick RM, McAuliffe V, Holden-Wiltse J, Crumpacker C, Liebes L, Stein DS, Meehan P, Hussey S, Forcht J, Valentine FT. Phase I studies of hypericin, the active compound in St. John's Wort, as an antiretroviral agent in HIV-infected adults. AIDS Clinical Trials Group Protocols 150 and 258. Ann Intern Med 1999; 130: 510-514

35 Maury W, Price JP, Brindley MA, Oh C, Neighbors JD, Wiemer DF, Wills N, Carpenter S, Hauck C, Murphy P, Widrlechner MP, Delate K, Kumar G, Kraus GA, Rizshsky L, Nikolau B. Identification of light-independent inhibition of human immunodeficiency virus-1 infection through bioguided fractionation of Hypericum perforatum. Virol J 2009; 6: 101

36 López-Chicón P, Paz-Cristobal MP, Rezusta A, Aspiroz C, Royo-Cañas M, Andres-Ciriano E, Gilaberte Y, Agut M, Nonell S. On the mechanism of Candida spp. photoinactivation by hypericin. Photochem Photobiol Sci 2012; 11: 1099-1107

37 Khosa RL, Bhatia N. Antifungal effect of Hypericum perforatum Linn. J Sci Res Plant Med 1982; 3: 49-50

38 Hunt EJ, Lester CE, Lester EA, Tackett RL. Effect of St. John's wort on free radical production. Life Sci 2001; 69: 181-190

39 Benedi J, Arroyo R, Romero C, Martin-Aragon S, Villar AM. Antioxidant properties and protective effects of a standardized extract of Hypericum perforatum on hydrogen peroxide-induced oxidative damage in PC12 cells. Life Sci 2004; 75: 1263-1276

40 Jang MH, Lee TH, Shin MC, Bahn GH, Kim JW, Shin DH, Kim EH, Kim CJ. Protective effect of Hypericum perforatum Linn (St. John's wort) against hydrogen peroxide-induced apoptosis on human neuroblastoma cells. Neurosci Lett 2002; 329: 177-180

41 Sagratini G, Ricciutelli M, Vittori S, Oztürk N, Oztürk Y, Maggi F. Phytochemical and antioxidant analysis of eight Hypericum taxa from Central Italy. Fitoterapia 2008; 79: 210-213

42 Rainha N, Lima E, Baptista J. Comparison of the endemic Azorean Hypericum foliosum with other Hypericum species: antioxidant activity and phenolic profile. Nat Prod Res 2011; 25: 123-135

$43 \mathrm{Zou} Y$, Lu Y, Wei D. Antioxidant activity of a flavonoid-rich extract of Hypericum perforatum L. in vitro. J Agric Food Chem 2004; 52: 50325039

44 Meinke MC, Schanzer S, Haag SF, Casetti F, Müller ML, Wölfle U, Kleemann A, Lademann J, Schempp CM. In vivo photoprotective and anti-inflammatory effect of hyperforin is associated with high antioxidant activity in vitro and ex vivo. Eur J Pharm Biopharm 2012; 81: 346-350

45 Onoue S, Seto $Y$, Ochi $M$, Inoue R, Ito H, Hatano T, Yamada S. In vitro photochemical and phototoxicological characterization of major constituents in St. John's Wort (Hypericum perforatum) extracts. Phytochemistry 2011; 72: 1814-1820

46 Schempp CM, Müller K, Winghofer B, Schulte-Mönting J, Simon JC. Singledose and steady-state administration of Hypericum perforatum extract (St John's Wort) does not influence skin sensitivity to UV radiation, visible light, and solar-simulated radiation. Arch Dermatol 2001; 137: 512-513

47 Traynor NJ, Beattie PE, Ibbotson SH, Moseley H, Ferguson J, Woods JA. Photogenotoxicity of hypericin in HaCaT keratinocytes: implications for St. John's Wort supplements and high dose UVA-1 therapy. Toxicol Lett $2005 ; 158: 220-224$

48 Schmitt LA, Liu Y, Murphy PA, Petrich JW, Dixon PM, Birt DF. Reduction in hypericin-induced phototoxicity by Hypericum perforatum extracts and pure compounds. J Photochem Photobiol B 2006; 85: 118-130

49 Boiy A, Roelandts $R$, van den Oord J, de Witte PA. Photosensitizing activity of hypericin and hypericin acetate after topical application on normal mouse skin. Br J Dermatol 2008; 158: 360-369

50 Sosa S, Pace R, Bornancin A, Morazzoni P, Riva A, Tubaro A, Della Loggia $R$. Topical anti-inflammatory activity of extracts and compounds from Hypericum perforatum L. J Pharm Pharmacol 2007; 59: 703-709

51 Kang BY, Chung SW, Kim TS. Inhibition of interleukin-12 production in lipopolysaccharide-activated mouse macrophages by hpyericin, an active component of Hypericum perforatum. Planta Med 2001; 67: 364366

52 Albert D, Zündorf I, Dingermann T, Müller WE, Steinhilber D, Werz O. Hyperforin is a dual inhibitor of cyclooxygenase-1 and 5-lipoxygenase. Biochem Pharmacol 2002; 64: 1767-1775

53 Hammer KD, Hillwig ML, Solco AK, Dixon PM, Delate K, Murphy PA, Wurtele ES, Birt DF. Inhibition of prostaglandin $\mathrm{E}(2)$ production by anti-inflammatory Hypericum perforatum extracts and constituents in RAW264.7 Mouse Macrophage Cells. J Agric Food Chem 2007; 55: 7323-7331

54 Koeberle A, Rossi A, Bauer J, Dehm F, Verotta L, Northoff H, Sautebin L, Werz 0 . Hyperforin, an Anti-Inflammatory Constituent from St. John's
Wort, Inhibits Microsomal Prostaglandin E(2) Synthase-1 and Suppresses Prostaglandin E(2) Formation in vivo. Front Pharmacol 2011; 2: 7

55 Feisst C, Pergola C, Rakonjac M, Rossi A, Koeberle A, Dodt G, Hoffmann M, Hoernig C, Fischer L, Steinhilber D, Franke L, Schneider G, Rådmark O, Sautebin $L$, Werz 0 . Hyperforin is a novel type of 5-lipoxygenase inhibitor with high efficacy in vivo. Cell Mol Life Sci 2009; 66: 2759-2771

56 Heilmann J, Winkelmann K, Sticher O. Studies on the antioxidative activity of phloroglucinol derivatives isolated from Hypericum species. Planta Med 2003; 69: 202-206

57 Cabrelle A, Dell'Aica I, Melchiori L, Carraro S, Brunetta E, Niero R, Scquizzato E, D'Intino G, Calzà L, Garbisa S, Agostini C. Hyperforin down-regulates effector function of activated T lymphocytes and shows efficacy against Th1-triggered CNS inflammatory-demyelinating disease. J Leukoc Biol 2008; 83: 212-219

58 Schempp CM, Winghofer B, Lüdtke R, Simon-Haarhaus B, Schöpf E, Simon JC. Topical application of St John's wort (Hypericum perforatum L.) and of its metabolite hyperforin inhibits the allostimulatory capacity of epidermal cells. Br J Dermatol 2000; 142: 979-984

59 Schempp CM, Simon-Haarhaus B, Simon JC. Phototoxic and apoptosisinducing capacity of pseudohypericin. Planta Med 2002; 68: 171-173

60 Schempp CM, Simon-Haarhaus B, Termeer CC, Simon JC. Hypericin photo-induced apoptosis involves the tumor necrosis factor-related apoptosis-inducing ligand (TRAIL) and activation of caspase-8. FEBS Lett 2001; 493: 26-30

61 Sharma KV, Davids LM. Hypericin-PDT-induced rapid necrotic death in human squamous cell carcinoma cultures after multiple treatment. Cell Biol Int 2012; 36: 1261-1266

62 Sharma KV, Davids LM. Depigmentation in melanomas increases the efficacy of hypericin-mediated photodynamic-induced cell death. Photodiagnosis Photodyn Ther 2012; 9: 156-163

63 Menichini G, Alfano C, Marrelli M, Toniolo C, Provenzano E, Statti GA, Nicoletti M, Menichini F, Conforti F. Hypericum perforatum L. subsp. perforatum induces inhibition of free radicals and enhanced phototoxicity in human melanoma cells under ultraviolet light. Cell Prolif 2013; 46: 193-202

64 Huntosova V, Nadova Z, Dzurova L, Jakusova V, Sureau F, Miskovsky P. Cell death response of U87 glioma cells on hypericin photoactivation is mediated by dynamics of hypericin subcellular distribution and its aggregation in cellular organelles. Photochem Photobiol Sci 2012; 11: $1428-1436$

65 Ritz R, Scheidle C, Noell S, Roser F, Schenk M, Dietz K, Strauss WSL. In vitro comparison of hypericin and 5-aminolevulinic acid-derived protoporphyrin IX for photodynamic inactivation of medulloblastoma cells. PLOS ONE 2012; 7: e51974

66 Šemeláková M, Mikeš J, Jendželovský R, Fedoročko P. The pro-apoptotic and anti-invasive effects of hypericin-mediated photodynamic therapy are enhanced by hyperforin or aristoforin in HT-29 colon adenocarcinoma cells. J Photochem Photobiol B 2012; 117: 115-125

67 Schempp CM, Kirkin V, Simon-Haarhaus B, Kersten A, Kiss J, Termeer CC, Gilb B, Kaufmann T, Borner C, Sleeman JP, Simon JC. Inhibition of tumour cell growth by hyperforin, a novel anticancer drug from St. John's wort that acts by induction of apoptosis. Oncogene 2002; 21: 1242-1250

68 Merhi F, Tang R, Piedfer M, Mathieu J, Bombarda I, Zaher M, Kolb JP, Billard C, Bauvois B. Hyperforin inhibits Akt1 kinase activity and promotes caspase-mediated apoptosis involving Bad and Noxa activation in human myeloid tumor cells. PLoS One 2011; 6: e25963

69 Hostanska K, Reichling J, Bommer S, Weber M, Saller R. Hyperforin a constituent of St John's wort (Hypericum perforatum L.) extract induces apoptosis by triggering activation of caspases and with hypericin synergistically exerts cytotoxicity towards human malignant cell lines. Eur J Pharm Biopharm 2003; 56: 121-132

70 Schempp CM, Kiss J, Kirkin V, Averbeck M, Simon-Haarhaus B, Kremer B, Termeer CC, Sleeman J, Simon JC. Hyperforin acts as an angiogenesis inhibitor. Planta Med 2005; 71: 999-1004

71 Dajas F. Life or death: neuroprotective and anticancer effects of quercetin. J Ethnopharmacol 2012; 143: 383-396

72 Romagnolo DF, Selmin OI. Flavonoids and cancer prevention: a review of the evidence. J Nutr Gerontol Geriatr 2012; 31: 206-238

73 Mukherjee PK, Verpoorte R, Suresh B. Evaluation of in-vivo wound healing activity of Hypericum patulum (Family: Hypericaceae) leaf extract on different wound model in rats. J Ethnopharmacol 2000; 70: 315321 
74 Süntar IP, Akkol EK, Yilmazer D, Baykal T, Kirmizibekmez H, Alper M, Yesilada $E$. Investigations on the in vivo wound healing potential of Hypericum perforatum L. J Ethnopharmacol 2010; 127: 468-477

75 Castro FC, Magre A, Cherpinski R, Zelante PM, Neves LM, Esquisatto MA, Mendonça FA, Santos GM. Effects of microcurrent application alone or in combination with topical Hypericum perforatum L. and Arnica montana L. on surgically induced wound healing in Wistar rats. Homeopathy 2012; 101: 147-153

76 Öztürk N, Korkmaz S, Ozturk Y. Wound-healing activity of St. John's Wort (Hypericum perforatum L.) on chicken embryonic fibroblasts. J Ethnopharmacol 2006; 111: 33-39

77 Hostanska K, Rostock M, Melzer J, Baumgartner S, Saller R. A homeopathic remedy from arnica, marigold, St. John's wort and comfrey accelerates in vitro wound scratch closure of NIH 3 T3 fibroblasts. BMC Complement Altern Med 2012; 12: 100

78 Leuner K, Kraus M, Woelfle U, Beschmann H, Harteneck C, Boehncke WH, Schempp CM, Müller WE. Reduced TRPC channel expression in psoriatic keratinocytes is associated with impaired differentiation and enhanced proliferation. PLoS One 2011; 6: e14716

79 Müller M, Essin K, Hill K, Beschmann H, Rubant S, Schempp CM, Gollasch M, Boehncke WH, Harteneck C, Müller WE, Leuner K. Specific TRPC6 channel activation, a novel approach to stimulate keratinocyte differentiation. J Biol Chem 2008; 283: 33942-33954

80 Chen WC, Liou SS, Tzeng TF, Lee SL, Liu IM. Effect of topical application of chlorogenic acid on excision wound healing in rats. Planta Med 2013 Apr 8. [Epub ahead of print]

81 CEBM - Oxford Centre for Evidence Based Medicine. Levels of evidence. March 2009. Available at http://www.cebm.net/?o=1025. Accessed April 30, 2013

82 Saljic J. Ointment for the treatment of burns. Ger Offen 1975; 2: 406452

83 Lomagno P, Lomagno RC. Activity of Hypericum perforatum oil in the treatment of the bed sores in old people. Fitoterapia 1979; 50: 201205

84 Kundaković T, Milenković M, Zlatković S, Nikolić V, Nikolić G, Binić I. Treatment of venous ulcers with the herbal-based ointment Herbadermal ${ }^{\circledR}$ : a prospective non-randomized pilot study. Forsch Komplementmed 2012; 19: 26-30

85 Lavagna SM, Secci D, Chimenti P, Bonsignore L, Ottaviani A, Bizzarri B. Efficacy of Hypericum and Calendula oils in the epithelial reconstruction of surgical wounds in childbirth with caesarean section. Farmaco 2001; 56: 451-453
86 Samadi S, Khadivzadeh T, Emami A, Moosavi NS, Tafaghodi M, Behnam $H R$. The effect of Hypericum perforatum on the wound healing and scar of cesarean. J Alternat Complement Med 2010; 16: 113-117

87 Läuchli S, Hafner J, Wehrmann C, French LE, Hunziker T. Post-surgical scalp wounds with exposed bone treated with a plant-derived wound therapeutic. J Wound Care 2012; 21: 228, 230, 232-233

88 Najafizadeh P, Hashemian F, Mansouri P, Farshi S, Surmaghi MS, Chalangari $R$. The evaluation of the clinical effect of topical St Johns wort (Hypericum perforatum $\mathrm{L}$.) in plaque type psoriasis vulgaris: a pilot study. Australas J Dermatol 2012; 53: 131-135

89 Mannel M, Koytchev R, Dundarov S. Oral hypericum extract LI 160 is an effective treatment of recurrent herpes genitalis and herpes labialis. Phytomedicine 2000; 7 (Suppl. 2): 17

90 Clewell A, Barnes M, Endres JR, Ahmed M, Ghambeer DK. Efficacy and tolerability assessment of a topical formulation containing copper sulfate and Hypericum perforatum on patients with herpes skin lesions: a comparative, randomized controlled trial. J Drugs Dermatol 2012; 11: 209-215

91 Alecu M, Ursaciuc C, Hãlãlãu F, Coman G, Merlevede W, Waelkens E, de Witte P. Photodynamic treatment of basal cell carcinoma and squamous cell carcinoma with hypericin. Anticancer Res 1998; 18: 46514654

92 Dirschka T and AK-CT002 Study Group. Photodynamic therapy with BF-200 ALA for the treatment of actinic keratosis: results of a multicentre, randomized, observer-blind phase III study in comparison with a registered methyl-5-aminolaevulinate cream and placebo. $\mathrm{Br}$ J Dermatol 2012; 166: 137-146

93 Heinrich U, Tronnier H. Wirksamkeit und Verträglichkeit eines Johanniskraut-Extraktes zur Pflege der atopischen Haut. Kosmetische Med 2003; $124: 133-136$

94 Arndt S, Haag SF, Kleemann A, Lademann J, Meinke MC. Radical protection in the visible and infrared by a hyperforin-rich cream - in vivo versus ex vivo methods. Exp Dermatol 2013; 22: 354-357

95 Haag SF, Tscherch K, Arndt S, Kleemann A, Gersonde I, Lademann J, Rohn $S$, Meinke MC. Enhancement of skin radical scavenging activity and stratum corneum lipids after the application of a hyperforin-rich cream. Eur J Pharm Biopharm 2013; Jun 26 [pii: S0939-6411(13) 00235-X]. DOI: 10.1016/j.ejpb.2013.06.016 [Epub ahead of print]

96 CIR - Cosmetic Ingredient Review. Final report on the safety assessment of Hypericum perforatum extract and Hypericum perforatum oil. Int J Toxicol 2001; 20 (Suppl. 2): 31-39

97 Reuter J, Huyke C, Scheuvens H, Ploch M, Neumann K, Jakob T, Schempp $C M$. Skin tolerance of a new bath oil containing St. John's wort extract. Skin Pharmacol Physiol 2008; 21: 306-311 